\title{
O que afasta pretos e pardos da representação política? Uma análise a partir das eleições legislativas de 2014
}

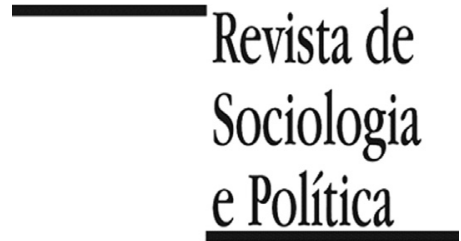

DOI 10.1590/1678-987317256107

\author{
Luiz Augusto Campos e Carlos Machado
}

\begin{abstract}
Resumo
Mesmo um observador leigo da política brasileira é capaz de constatar que os pretos e pardos estão excluídos das suas arenas decisórias. Contudo, a ausência de registros sobre a cor/raça de nossos políticos sempre dificultou o dimensionamento dessa sub-representação e as suas possíveis causas. Desde as eleições de 2014, porém, o Tribunal Superior Eleitoral computa a raça/cor dos candidatos registrados, o que permite contornar parcialmente essas dificuldades. Neste trabalho, recorremos a esses dados para dimensionar quão sub-representados pretos e pardos estão na Câmara dos Deputados e, sobretudo, testar algumas hipóteses explicativas de tal fenômeno. Os resultados indicam que as chances eleitorais de pretos e pardos são menores em relação às de brancos por causa de múltiplos fatores: (1) classe de origem, (2) acesso a recursos de campanha e (3) estruturas partidárias competitivas. Tudo isso sugere que medidas que busquem tornar a representação política mais diversa devem considerar a complexidade dos obstáculos interpostos a pretos e pardos.
\end{abstract}

PALAVRAS-CHAVE: raça; negros; representação política; eleições; recrutamento político.

Recebido em 11 de Novembro de 2015. Aceito em 17 de Março de 2016.

\section{Introdução ${ }^{1}$}

A ssim como outros espaços de poder e prestígio, a representação política é uma esfera majoritariamente branca no Brasil. Mas se a ausência de pretos e pardos ${ }^{2}$ é relativamente evidente, o mesmo não pode ser dito sobre o diagnóstico de suas causas. Embora seja possível conjecturar que ela reflita o ciclo cumulativo de desigualdades, que oblitera a ascensão de pretos e pardos em outras esferas sociais, a ausência de registros sobre a cor/raça dos políticos brasileiros sempre dificultou a produção de evidências mais robustas que ajudassem a determinar os mecanismos subjacentes a essa situação. Disso resulta que as pesquisas sobre a dimensão dessa sub-representação e os fatores que a geram sempre tiveram de imaginar metodologias complexas para gerar resultados limitados.

Nas eleições de 2014, porém, o Tribunal Superior Eleitoral (TSE) computou, pela primeira vez em sua história, a raça/cor dos candidatos registrados. Além de armazenar uma variável fundamental para estudos de estratificação no país, essa inclusão permite o cruzamento dessa clivagem com todas as outras já computadas pelo TSE tradicionalmente, como renda do candidato, receitas de campanha, sexo, estado civil, ocupação etc. Esses dados permitem não apenas estimar a magnitude da sub-representação política de pretos e pardos, mas também aventar hipóteses explicativas para tal sub-representação.

Neste trabalho, recorremos a esses dados para dimensionar a sub-representação de pretos e pardos nas últimas eleições nacionais e, sobretudo, testar algumas hipóteses que podem ajudar a explicar tal fenômeno. Análises preliminares já indicam que a presença de pretos e pardos nas listas de candidaturas está aquém da proporção desses grupos na população de modo geral, embora tal 
"pretos" ou "pardos" em um só grupo. discrepância não seja tão grande (Campos \& Machado 2015a; 2015b; Bueno \& Dunning 2013). Com todas as limitações metodológicas a que os estudos sobre essa questão estavam condicionados até 2014, a bibliografia sobre o tema contém outras hipóteses explicativas para tal sub-representação que, agora, podem ser submetidas a testes mais robustos.

Uma primeira hipótese relaciona a sub-representação de pretos e pardos como expressão das desigualdades sociais para além das eleições, desigualdades essas que excluiriam esses contingentes da vida política e, assim, reduziriam sensivelmente a oferta de candidatos não brancos nas eleições. Uma segunda hipótese entende que o filtro que exclui pretos e pardos tem menos a ver com um alheamento político dos mesmos, estando mais relacionado à posse desigual entre brancos e não brancos de recursos sociais eleitoralmente valiosos, como nível educacional, origem de classe etc. Uma terceira hipótese explica a sub-representação de pretos e pardos como resultado de um viés da distribuição de recursos de campanha, os quais, como se sabe, costumam ter enorme impacto na distribuição de votos. Finalmente, uma quarta hipótese atribui essa sub-representação ao acesso diferencial que esses contingentes têm às estruturas partidárias que garantem maior expressão eleitoral.

Algumas dessas hipóteses foram avaliadas por Campos e Machado (2015a) a partir de uma pesquisa piloto com os candidatos a vereador em 2012 nos dois maiores colégios eleitorais brasileiros, Rio de Janeiro e São Paulo. Entretanto, como a raça/cor dos candidatos foi determinada por heteroclassificação, a comparação com os demais dados sobre cor/raça da população brasileira ficou prejudicada, já que as pesquisas oficiais sobre o tema costumam utilizar a autoclassificação. Ademais, o escopo da pesquisa ficou restrito às eleições municipais em duas cidades. Diante disso, o objetivo deste artigo é testar as quatro hipóteses supracitadas (oferta de candidatos, perfil social, recursos de campanha e acesso a partidos competitivos) a partir dos dados disponibilizados pelo TSE para as eleições nacionais de 2014. Focaremos apenas as disputas eleitorais para o cargo de deputado federal, deixando para uma outra oportunidade a análise da disputa de outros cargos.

Todos esses dados servem para subsidiar um debate mais normativo, que busca responder (1) em que medida a exclusão de pretos e pardos da representação deve ser entendida como um traço injusto ou antidemocrático do nosso sistema político e (2) até que ponto é legítimo e adequado pensar em políticas para a inclusão de pretos e pardos na representação. No âmbito da teoria política, há uma grande quantidade de trabalhos dedicados a pensar a pertinência das políticas de inclusão de grupos na representação (Phillips 1995; Norris 1997; Mansbridge 1999; Williams 2000; Young 2000). Ainda que essa discussão seja eventualmente aventada em debates legislativos ligados à reforma política, os projetos de lei em tramitação no Congresso Nacional foram formulados sem um conhecimento mínimo dos processos de alheamento dos não brancos da representação. Assim sendo, diagnosticar os nós da estratificação política que tornam a representação um espaço majoritariamente branco é fundamental para avaliar e formular mecanismos institucionais capazes de mitigar essa desigualdade.

\section{Oferta de candidaturas}

Os dados disponibilizados pelo TSE indicam que a soma dos candidatos e candidatas pretos e pardos nas listas partidárias se distanciou da participação desses dois contingentes na população nacional, mas não de forma muito expressiva. Em 2014, 59,4\% dos candidatos se declararam brancos, contra $47,9 \%$ da população brasileira, de acordo com o censo de $2010 ; 30,2 \%$ se declararam pardos contra $43,2 \%$ da população geral; e $9,6 \%$ se declararam 
${ }^{3}$ Se somados, esses percentuais não atingem $100 \%$ pois eles não consideram a proporção de candidatos que se declararam amarelos e indígenas. Como tais contingentes correspondem a um percentual pequeno da população e as análises que se seguem são majoritariamente estatísticas, não foram considerados os amarelos e indígenas. pretos contra 7,4\% da população ${ }^{3}$. Ou seja, os candidatos brancos e os pretos aparecem sobrerrepresentados em relação à população nacional, com uma diferença de $11,5 \%$ e $2,1 \%$, respectivamente; e os candidatos pardos aparecem sub-representados nas listas, com uma diferença negativa de 13,1\% em relação à população. Essas distâncias aumentam substantivamente, contudo, quando analisamos os percentuais de candidatos eleitos de cada grupo racial. Os brancos correspondem a 79,9\% dos deputados federais eleitos em 2014, os pardos correspondem $16 \%$ e os pretos $4,1 \%$. O Gráfico 1 , a seguir, representa visualmente os percentuais de cada um dos três grupos nos três estratos:

Grosso modo, as diferenças entre o percentual de candidatos e a população geral são importantes, mas não o suficiente para explicar a sub-representação dos pretos e pardos efetivamente eleitos, apresentando uma defasagem de $22 \%$ em relação às candidaturas. Há mesmo uma leve sobrerrepresentação de pretos nas listas, vantagem numérica que, contudo, não permanece depois de composta a representação. Logo, não é possível atribuir a sub-representação de pretos e pardos na Câmara à mesma sub-representação nas listas partidárias. O impacto maior da sub-representação encontra-se entre os eleitos, pois a defasagem de eleitos em relação a candidaturas chega a $51 \%$, evidenciando que entre a nomeação de um candidato e a sua eleição persiste um filtro mais potente para a restrição de não brancos do que aquele operado para a apresentação nas listas partidárias.

Porém, essa hipótese tem de ser avaliada levando-se em conta o fato de que as desigualdades raciais assumem formas diferentes a depender da região brasileira analisada, o que provavelmente tem impactos distintos em cada unidade da federação (Meneguello, Mano \& Gorski 2012). Ademais, as unidades da federação costumam variar em relação à participação demográfica da população preta e parda, o grau de articulação política desses grupos e sua penetração nas estruturas partidárias de cada localidade etc. Isso fica claro quando observamos a relação entre o percentual de não brancos (soma de pretos e pardos) na população de cada estado, na soma de suas listas partidárias, e entre os eleitos. Tal relação pode ser mensurada com base em um cálculo de defasagem entre a proporção de não brancos nas candidaturas e a proporção de não brancos na população; ou de não brancos entre os eleitos e não brancos entre os

Gráfico 1 - Percentual de cada grupo racial na população, dentre os candidatos e eleitos para deputado federal (valores percentuais)

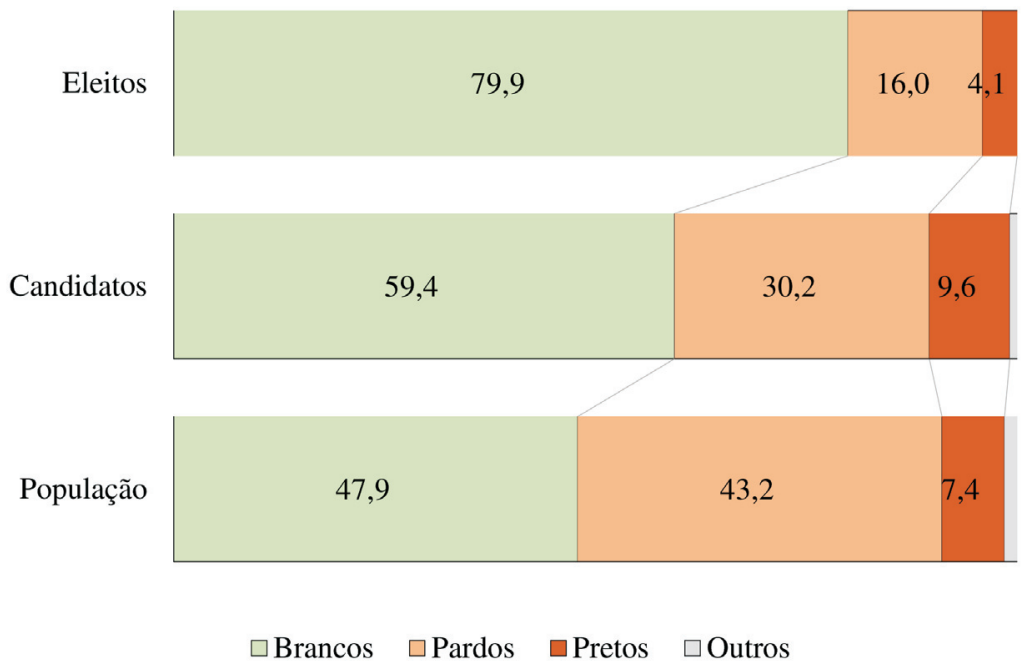

Fonte: Os autores, a partir do Tribunal Superior Eleitoral (2017). 
${ }^{4}$ Os autores gostariam de agradecer o/a parecerista anônimo/a por esta contribuição ao trabalho. candidatos, conforme a Tabela 1 a seguir. Trata-se da diferença entre o percentual da população em relação ao percentual das candidaturas dividido pelo valor total da população: O cálculo identifica qual é o peso da variação observada considerando o máximo de variação possível ${ }^{4}$.

Como é possível notar, as unidades da federação variam de forma considerável, não apenas no que se refere à participação da população não branca que a compõe (de casos com menos $20 \%$ como Santa Catariana e Rio Grande do Sul a casos com quase $80 \%$ como Amapá, Maranhão e Bahia), mas também no que tange à quantidade relativa de não brancos dentre os candidatos e eleitos. Em média, as unidades da federação elegem 31 pontos percentuais a menos de não brancos do que a participação desse contingente na sua população. Os cenários mais favoráveis à população não branca são observados no Acre, Pará e Amazonas. As menores taxas de eleitos não brancos - abaixo de $10 \%$ do total de

Tabela 1 - Percentual de cada grupo racial na população, dentre os candidatos e eleitos para deputado federal por unidade da federação

\begin{tabular}{|c|c|c|c|c|c|}
\hline & $\begin{array}{l}\text { Não brancos na } \\
\text { população (\%) }\end{array}$ & $\begin{array}{l}\text { Não brancos nas } \\
\text { candidaturas (\%) }\end{array}$ & $\begin{array}{c}\text { Não brancos dentre } \\
\text { os eleitos }(\%)\end{array}$ & $\begin{array}{c}\text { Defasagem relativa } \\
\text { de candidaturas e } \\
\text { população }(\%)\end{array}$ & $\begin{array}{c}\text { Defasagem relativa } \\
\text { de eleitos e } \\
\text { candidaturas }(\%)\end{array}$ \\
\hline $\mathbf{A M}$ & 79 & 65 & 58 & 17,7 & 10,8 \\
\hline $\mathbf{R R}$ & 79 & 67 & 33 & 15,2 & 50,7 \\
\hline $\mathbf{B A}$ & 78 & 65 & 40 & 16,7 & 38,5 \\
\hline MA & 78 & 58 & 29 & 25,6 & 50 \\
\hline PA & 78 & 65 & 59 & 16,7 & 9,2 \\
\hline $\mathbf{A C}$ & 76 & 71 & 67 & 6,6 & 5,6 \\
\hline $\mathbf{A P}$ & 76 & 68 & 54 & 10,5 & 20,6 \\
\hline PI & 76 & 67 & 33 & 11,8 & 50,7 \\
\hline TO & 75 & 39 & 46 & 48 & $-17,9$ \\
\hline SE & 72 & 55 & 33 & 23,6 & 40. \\
\hline $\mathbf{A L}$ & 68 & 54 & 33 & 20,6 & 38,9 \\
\hline $\mathbf{C E}$ & 68 & 51 & 22 & 25 & 56,9 \\
\hline RO & 65 & 54 & 38 & 16,9 & 29,6 \\
\hline MT & 63 & 47 & 21 & 25,4 & 55,3 \\
\hline PE & 63 & 61 & 43 & 3,2 & 29,5 \\
\hline PB & 60 & 46 & 31 & 23,3 & 32,6 \\
\hline $\mathbf{R N}$ & 59 & 38 & 8 & 35,6 & 78,9 \\
\hline DF & 58 & 42 & 29 & 27,6 & 31 \\
\hline ES & 58 & 36 & 37 & 37,9 & $-2,8$ \\
\hline GO & 58 & 31 & 17 & 46,6 & 45,2 \\
\hline MG & 55 & 41 & 18 & 25,5 & 56,1 \\
\hline MS & 53 & 39 & 33 & 26,4 & 15,4 \\
\hline $\mathbf{R J}$ & 53 & 45 & 16 & 15,1 & 64,4 \\
\hline SP & 36 & 27 & 7 & 25 & 74,1 \\
\hline PR & 30 & 15 & 13 & 50 & 13,3 \\
\hline $\mathbf{R S}$ & 17 & 10 & 2 & 41,2 & 80 \\
\hline SC & 16 & 11 & 0 & 31,3 & 100 \\
\hline
\end{tabular}

Fonte: Os autores, a partir do Tribunal Superior Eleitoral (2017). 
eleitos em cada distrito - ocorrem nos estados mais ao sul do país (SP, RS e SC), onde o contingente populacional não branco é o menor do país, além do Rio Grande do Norte, onde apesar de 59\% da população ser não branca, o mesmo grupo obtém apenas $8 \%$ das cadeiras em disputa. Isso já indica outro dado importante a ser destrinchado: a relação entre o tamanho da população não branca e a proporção de eleitos não brancos não apresenta uma correlação perfeita, havendo situações bastante díspares. Essa informação demanda um olhar mais detalhado sobre a variação entre população, candidaturas e eleitos.

É possível observar estados como Roraima e Maranhão, onde apesar da elevada população não branca, há uma defasagem entre eleitos e candidatos que chega a 50\%, mesmo que a defasagem entre candidaturas e população não seja muito elevada (respectivamente 16,7\% e 25,6\%). Tocantins, por sua vez, apesar de apresentar um número maior de eleitos não brancos em comparação às candidaturas do mesmo perfil, com valor negativo no indicador de defasagem $(-17,9 \%)$, apresenta uma das mais elevadas taxas de defasagem entre candidaturas e população com $48 \%$, valor superado apenas pela situação de Paraná (50\%) e próxima a de Goiás (46,6\%). O contexto mais igualitário certamente é observado no Acre, onde a defasagem de candidaturas e de eleitos é baixa, respectivamente $6,6 \%$ e $5,6 \%$.

A princípio, seria possível conjecturar que a baixa representação de não brancos nos estados mais ao sul do Brasil seria decorrente do baixo quantitativo populacional deste grupo em seus estados. Entretanto, ao se comparar o peso da população não branca com a participação desse contingente entre os eleitos, há uma evidente desigualdade entre brancos e não brancos. A defasagem entre candidaturas e população em São Paulo é da ordem de $25 \%$, já a defasagem entre proporção de não brancos dentre os candidatos e os eleitos é da ordem de $74,1 \%$. Entre os estados da região Sul existem três padrões distintos de exclusão. No Paraná a restrição de participação de não brancos já ocorre na nomeação de candidaturas. A defasagem nas candidaturas é de $50 \%$, ao passo que a defasagem e, relação aos eleitos chega a 13,3\%. Rio Grade do Sul apresenta grande redução nas candidaturas $(41,2 \%)$, porém o efeito mais elevado ocorre quando comparamos candidaturas e eleitos, quando a defasagem chega a $80 \%$. Porém o caso mais emblemático é o de Santa Catarina. Apesar de apresentar o cenário menos restritivo para candidaturas da região Sul $(31,3 \%)$, nenhum candidato não branco foi eleito. Essas discrepâncias, portanto, não podem ser imputadas às idiossincrasias demográficas desses estados, mesmo porque o Rio Grande do Norte também apresentou uma alta defasagem entre os eleitos $(78,8 \%)$ apesar da discrepância menor entre população e candidaturas $(35,6 \%)$.

É difícil conjecturar causas para esse cenário, não apenas porque os contextos sociais e políticos são bastante diferentes nesses estados, mas também porque as bancadas costumam ser pequenas demais para inferimos alguma tendência estatística de sua composição. Mas de modo geral, é possível notar uma correlação entre o percentual de pretos e pardos na população e nas listas partidárias (Gráfico 2), apresentando valor de correlação de 0,92 . Isso provavelmente reflete que a composição das nominatas não se constitui em um filtro importante de exclusão de um grupo racial específico, muito embora já haja algum viés racial. Por outro lado, essa correlação cai quando comparamos o percentual de não brancos candidatos e aquele de eleitos (Gráfico 3), caso em que o valor do $R$ de Pearson chega a 0,8 - sugerindo que há mais disparidades na relação entre a proporção de não brancos eleitos e candidatos:

A despeito das diferenças entre as unidades federativas, a comparação entre os Gráficos 2 e 3 sugere que embora a oferta de candidaturas não brancas pareça refletir a participação desse contingente na população de cada unidade federativa, a eleição efetiva de candidatos com esse perfil é bem mais independente do 
Gráfico 2 - Scatterplot entre o percentual de não brancos na população em relação ao percentual de não brancos nas candidaturas

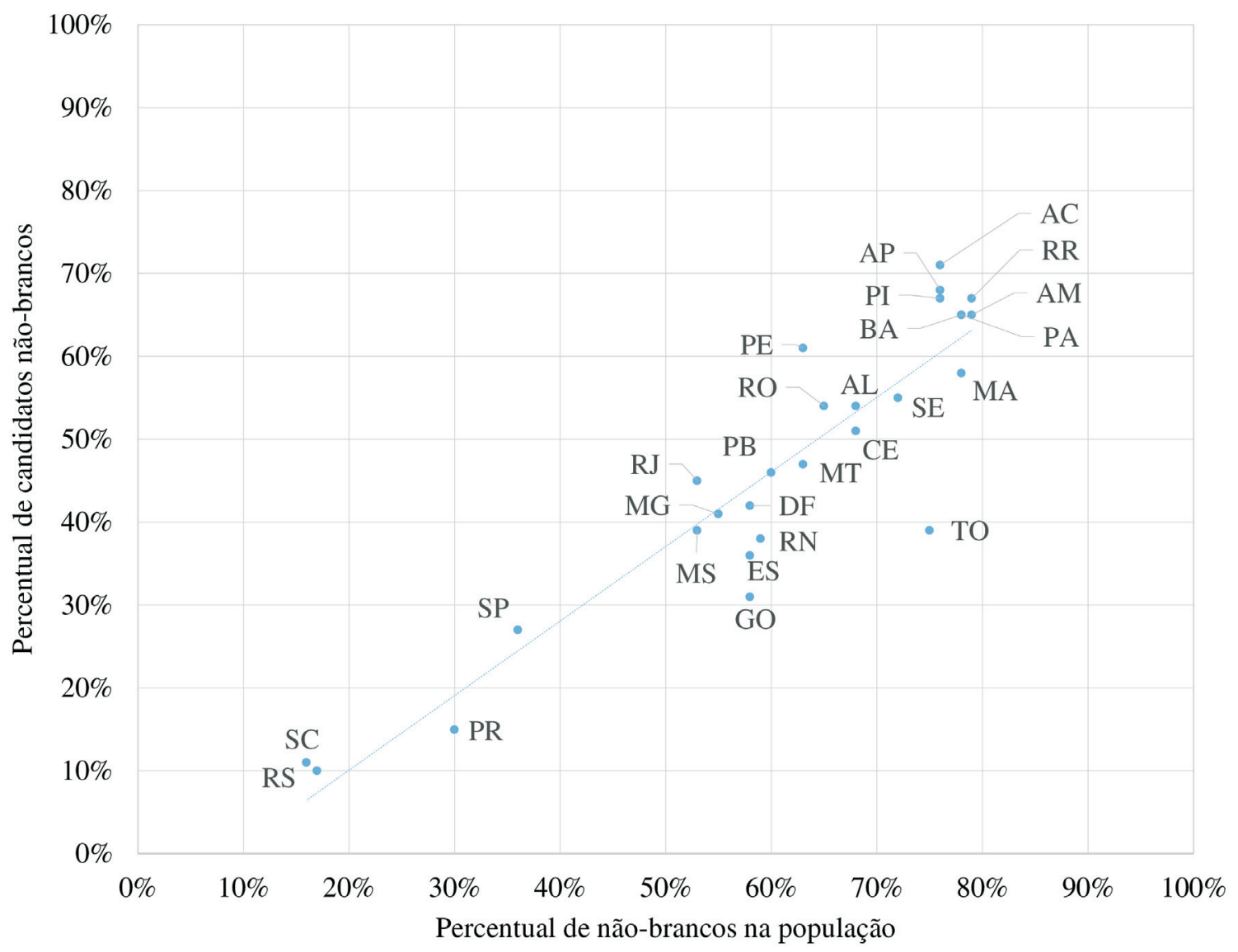

Fonte: Os autores, a partir do Tribunal Superior Eleitoral (2017).

perfil racial de cada estado. Assim, não seria possível atribuir completamente a sub-representação de não brancos na política brasileira apenas por uma oferta menor ou desigual de candidatos não brancos. Em praticamente todos os estados, o principal "corte" no percentual dos não brancos acontece quando analisamos os dados após as eleições. Ainda assim, isso não é suficiente para se imputar aos eleitores a responsabilidade pela exclusão dos candidatos não brancos da Câmara Federal. Antes, é preciso mensurar o peso que a posse desigual de recursos politicamente relevantes tem nas chances eleitorais dos pretos e pardos.

\section{Perfil Social}

Diante da sobreposição existente no Brasil entre estrutura de classe e fronteiras étnico-raciais, é preciso considerar, também, em que medida a subrepresentação política dos pretos e pardos reflete mais uma exclusão baseada na classe do que na raça. Desde as suas origens, a Sociologia Política tem demonstrado que a origem de classe tem um impacto importante no sucesso político de determinados candidatos (Michels 1982). Indivíduos que ocupam o topo da pirâmide social tendem a ter mais chances de ocupar o topo das hierarquias políticas (Gaxie 2012).

Contudo, se é de grande valia política os recursos financeiros e o tempo livre fartamente disponíveis para as classes mais abastadas, outros recursos sociais 
Gráfico 3 - Scatterplot entre o percentual de não brancos nas candidaturas e o percentual de não brancos eleitos

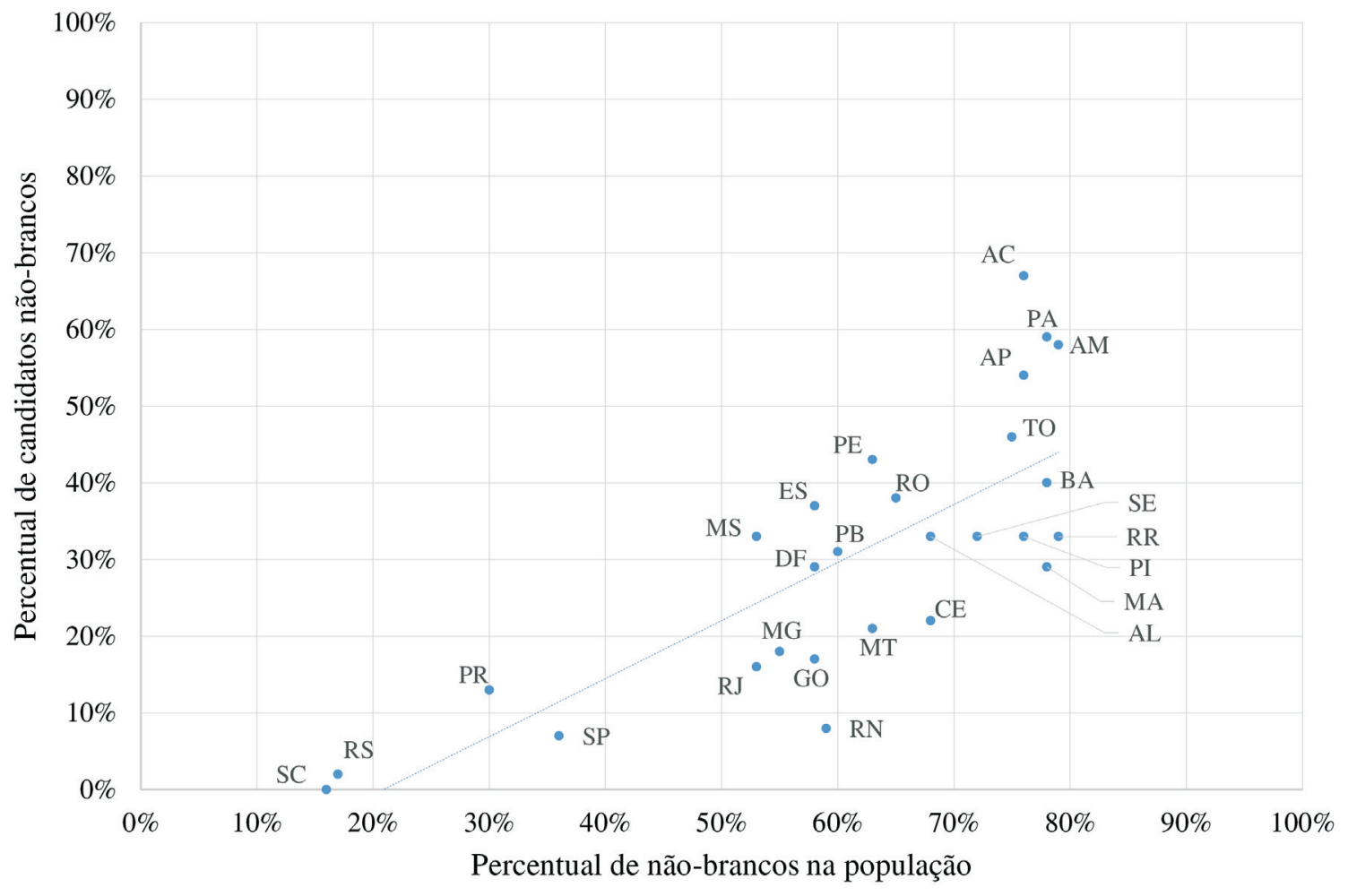

Fonte: Os autores, a partir do Tribunal Superior Eleitoral (2017).

são igualmente valorizados na disputa política. Algumas pesquisas vêm demonstrando que profissionais do Direito, médicos e professores costumam ter mais chances de se eleger do que profissionais em ocupações com status social semelhante. Ao que tudo indica, o contato direto com o público e as habilidades comunicativas cultivadas por esses profissionais são recursos valiosos nas disputas eleitorais (Norris \& Lovenduski 1997, p.110).

Levando em conta essas especificidades, trabalhamos aqui com uma divisão de classes sociais baseada não apenas no critério clássico da posição ocupada no mercado, mas que considera também a maior ou menor propensão política de determinadas ocupações (Codato, Costa \& Massimo 2014). A partir das ocupações profissionais compiladas pelo TSE, operamos com quatro categorias fundamentais: (1) classe baixa (trabalhadores rurais, manuais e domésticos, artesãos e técnicos de escritório com pouca formação); (2) classe média (técnicos com alta especialização, artistas, funcionários públicos de baixo escalão e comerciantes); (3) classe alta (profissionais diplomados no Ensino Superior, funcionários públicos de médio escalão e pequenos empresários); (4) classe muito alta (políticos já eleitos para outro cargo, grandes empresários e funcionários públicos que ocupam carreiras de Estado); (5) outros (ocupações não classificadas na base do TSE). Como esperado, o Gráfico 4 mostra que a distribuição dos não brancos pelas quatro classes sociais tende a decrescer à medida em que se sobe na hierarquia social politicamente valorizada.

Esses dados indicam o quão desigual é a seleção dos representantes políticos nacionais quando comparamos seu perfil socioeconômico com a população em geral. É verdade que a literatura especializada em recrutamento político vem indicando a tendência de que os parlamentos sejam uma espécie de imagem invertida da pirâmide social de seus países, em que as classes baixas formam 
Gráfico 4 - Distribuição dos candidatos a deputado federal de acordo com a classe social e a cor autodeclarada (valores percentuais)

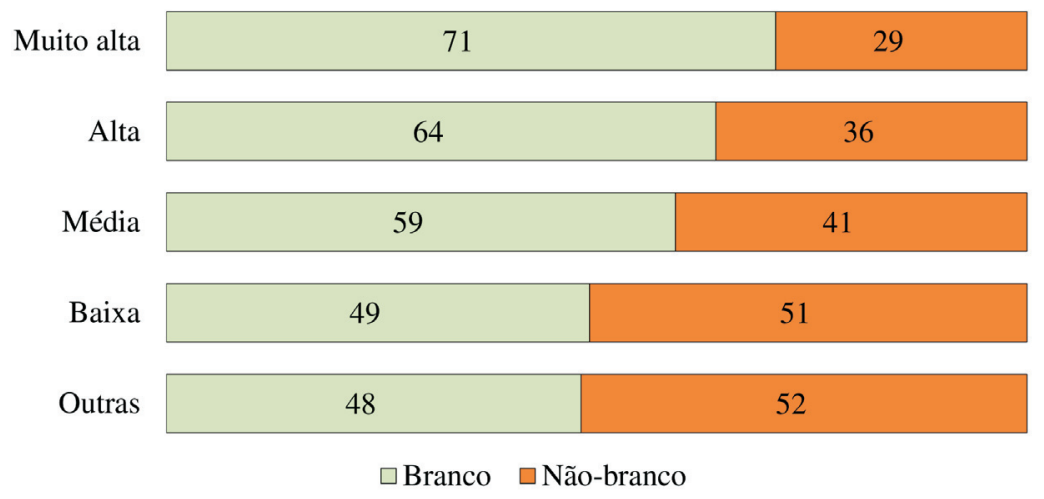

Fonte: Os autores, a partir do Tribunal Superior Eleitoral (2017).

uma ínfima minoria nos parlamentos contra uma sobrerrepresentação das classes mais altas (Gaxie 2012). Contudo, essa desigualdade parece maior no Brasil, país onde a burguesia, por exemplo, representa uma enorme parcela do parlamento, situação bem diferente daquela de outros países (Marques 2012). Vale destacar que mais da metade dos eleitos para a Câmara dos Deputados são oriundos da classe muito alta, justamente aquela com a menor representação de não brancos. Cerca de $40 \%$ dos candidatos classificados como de classe muito alta conseguiram se eleger, contra apenas $7 \%$ dos classificados como de classe alta e $2 \%$ dos classificados como sendo de classe baixa.

Portanto, é possível conjecturar que a sub-representação de pretos e pardos na Câmara reflita essa desigual composição racial das classes abastadas. Mas, para tal, é preciso descobrir, ainda, se as chances eleitorais dos candidatos no interior de cada classe variam de acordo com sua cor. Uma forma de fazer isso é comparar a votação média, recebida por cada grupo racial, dentro cada de classe. Como a distribuição das votações em cada unidade da federação é bastante assimétrica, utilizaremos não a votação média, mas o log do percentual de votos obtidos em cada colégio eleitoral. O Gráfico 5, a seguir, mostra os box-plots com a distribuição logarítmica do percentual de votos em cada uma das classes.

É possível perceber que a distribuição do log das votações de brancos e não brancos difere muito pouco. Apenas no último estrato de classe (muito alta), no qual é recrutado boa parte dos candidatos, há uma diferença levemente maior em benefício dos brancos. Isso quer dizer que as posições ocupadas pelos diferentes grupos de cor na escala de distribuição dos votos variam pouco, havendo uma diferença visível em benefício dos brancos apenas nos últimos escalões.

A Tabela 2 permite avaliar melhor a força dessa desigualdade, controlada pelos efeitos de outras variáveis relevantes do ponto de vista das características individuais das candidaturas. O modelo de regressão linear múltipla toma como variável dependente o log do percentual de votação por estado e como variáveis independentes quatro dummies: (1) declarar-se não branco, (2) ser mulher, (3) possuir diploma de ensino superior ou (4) ser de classe alta/muito alta.

Todos os modelos indicam que candidatos não brancos recebem votações menores às dos brancos, mesmo quando outras variáveis são consideradas a partir do modelo 2. Porém, observa-se uma redução do efeito exclusivo da identificação racial do candidato quando comparamos seu efeito simultanea- 
Gráfico 5 - Box-plots da distribuição do log do percentual de votação de acordo com a cor e classe do candidato

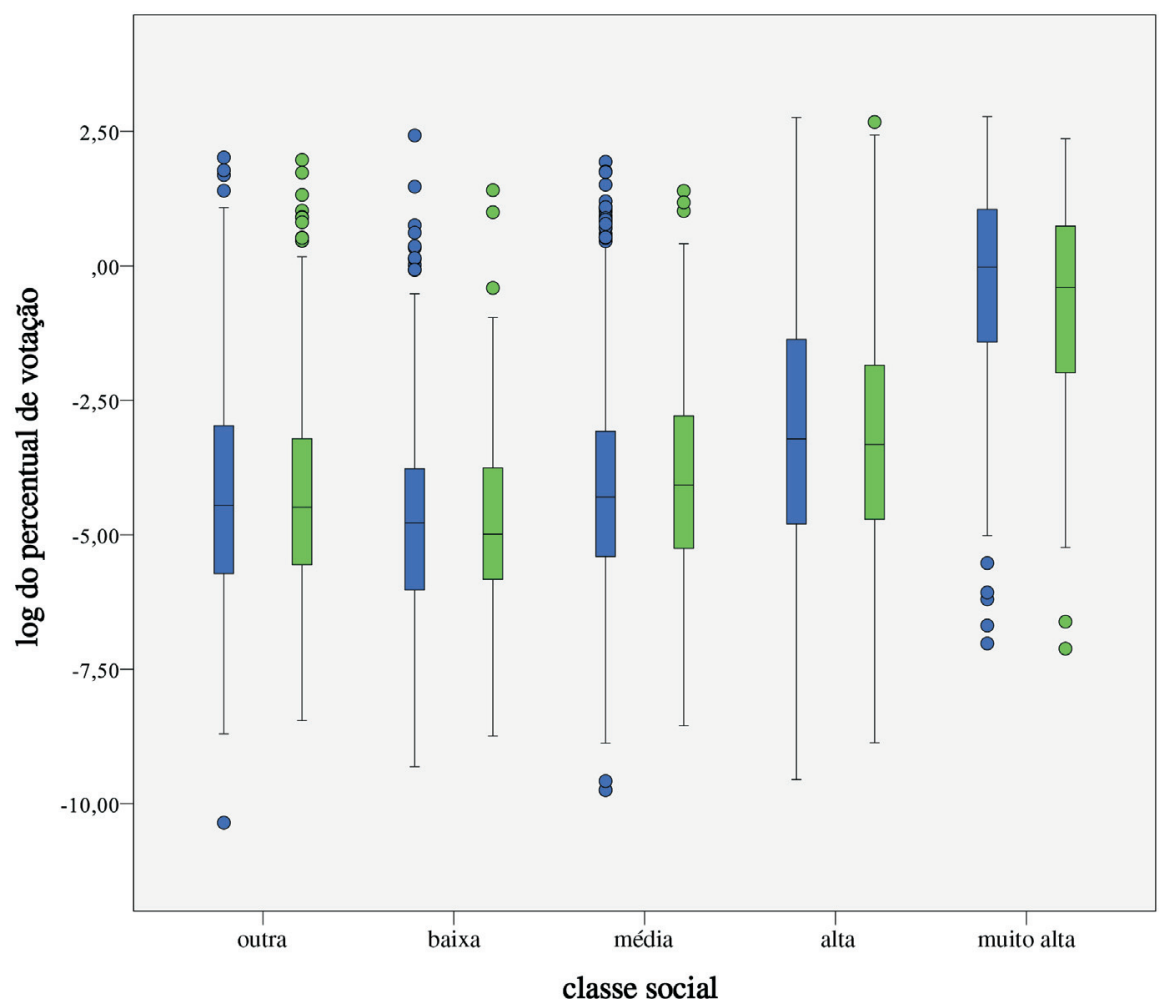

DESCRIÇÃO COR (BIN)

BRANCA

NÃO BRANCA

Fonte: Os autores, a partir do Tribunal Superior Eleitoral (2017).

Tabela 2 - Modelos de regressão linear para o log do percentual da votação obtida em relação ao estado (variável dependente)

\begin{tabular}{|c|c|c|c|c|c|c|c|c|}
\hline & \multicolumn{2}{|c|}{$\begin{array}{c}\text { Modelo } 1 \\
(\mathrm{R} 2 \text { ajust. }=\mathbf{0 , 0 1 1})\end{array}$} & \multicolumn{2}{|c|}{$\begin{array}{c}\text { Modelo } 2 \\
(\mathbf{R 2} \text { ajust.= 0,072) }\end{array}$} & \multicolumn{2}{|c|}{$\begin{array}{c}\text { Modelo } 3 \\
(\mathrm{R} 2 \text { ajust. }=\mathbf{0 , 1 2 4})\end{array}$} & \multicolumn{2}{|c|}{$\begin{array}{c}\text { Modelo } 4 \\
(\mathrm{R} 2 \text { ajust. }=\mathbf{0 , 1 7 3})\end{array}$} \\
\hline & B & std. B & B & std. B & B & std. B & B & std. B \\
\hline (constante) & $-3,34^{*}$ & & $-2,95^{*}$ & & $-3,92^{*}$ & & $-4,51 *$ & \\
\hline não branco & $-0,58^{*}$ & $-0,10$ & $-0,50 *$ & $-0,09$ & $-0,30 *$ & $-0,05$ & $-0,23$ & $-0,04$ \\
\hline feminino & & & $-1,50 *$ & $-0,25$ & $-1,42 *$ & $-0,23$ & $-1,20 *$ & $-0,20$ \\
\hline ensino superior & & & & & $1,33^{*}$ & 0,23 & $0,80^{*}$ & 0,14 \\
\hline classe alta/muito alta & & & & & & & $1,36^{*}$ & 0,24 \\
\hline
\end{tabular}

Fonte: Os autores, a partir do Tribunal Superior Eleitoral (2017).

* Significativo a $5 \%$

mente com o sexo, a passagem pelo Ensino Superior e o pertencimento à classe alta ou muito alta. Isso indica que a maior parte da desigualdade nas votações obtidas pelos candidatos se deve muito mais ao sexo e à origem de classe do que estritamente à sua raça, embora o efeito da raça ainda persista como negativo mesmo com o controle das demais variáveis, implicando, em média $23 \%$ menos votos para candidaturas não brancas.

Vale lembrar, no entanto, que as eleições de 2014 foram as primeiras a efetivamente obedecer às cotas de gênero nas listas partidárias, graças a uma resolução judicial que tornou mais difícil aos partidos burlarem essa norma. Embora poucas pesquisas tenham sido feitas sobre esse fato específico, alguns dados já sugerem que a inclusão de mais candidatas nas listas privilegiou mulheres com baixo capital político, o que certamente afeta o efeito maior de ser 
mulher no decréscimo da quantidade de votos recebidos. Sendo assim, é possível supor que o pertencimento de classe tem um efeito bem mais importante nesse modelo de regressão.

Entretanto, esse modelo desconsidera um dos fatores mais importantes nas eleições: a obtenção de recursos de campanha. Como diferentes pesquisas têm mostrado, a correlação entre os recursos obtidos pelos candidatos e as votações obtidas é bastante alta (Lemos, Marcelino \& Pederiva 2010). Nas últimas eleições, por exemplo, essa correlação, medida pelo R de Pearson, foi de 0,71. Se ignorarmos os montantes absolutos e compararmos apenas os rankings de votação e receitas, obtidos pelos logs das duas variáveis, tal correlação sobre para 0,91 . Essa alta correlação impede que consideremos em um mesmo modelo o efeito da raça em contraposição às receitas de campanha sobre as votações. É verdade, também, que tal correlação dificilmente pode ser tomada como uma relação unilateral de causa e efeito. Se parece intuitivo que candidatos com mais recursos de campanha obtenham mais votos, é igualmente razoável supor que candidatos com maiores chances de obter votações expressivas consigam atrair mais financiadores para suas campanhas. De todo modo, cabe observar se há alguma desigualdade de acesso a recursos de campanha entre candidatos brancos e não brancos, mesmo quando controlamos fatores como sexo, formação educacional ou pertencimento de classe.

\section{Recursos de Campanha}

5 Como em 2014 não havia nenhum limite para obtenção de recursos privados de campanha, a distribuição dos mesmos é tão assimétrica quanto a das votações. Daí a
Quando observamos a distribuição logarítmica do percentual de receita ${ }^{5}$ obtida pelos candidatos em função de sua classe, há um padrão levemente distinto da distribuição dos votos. De um lado, as diferenças entre brancos e não brancos continuam sendo pequenas, mas elas se mostram presentes em praticamente todas as classes, como indica o Gráfico 6. Essa tendência é confirmada

Gráfico 6 - Box-plots da distribuição do log do percentual de receita de acordo com a cor e classe do candidato

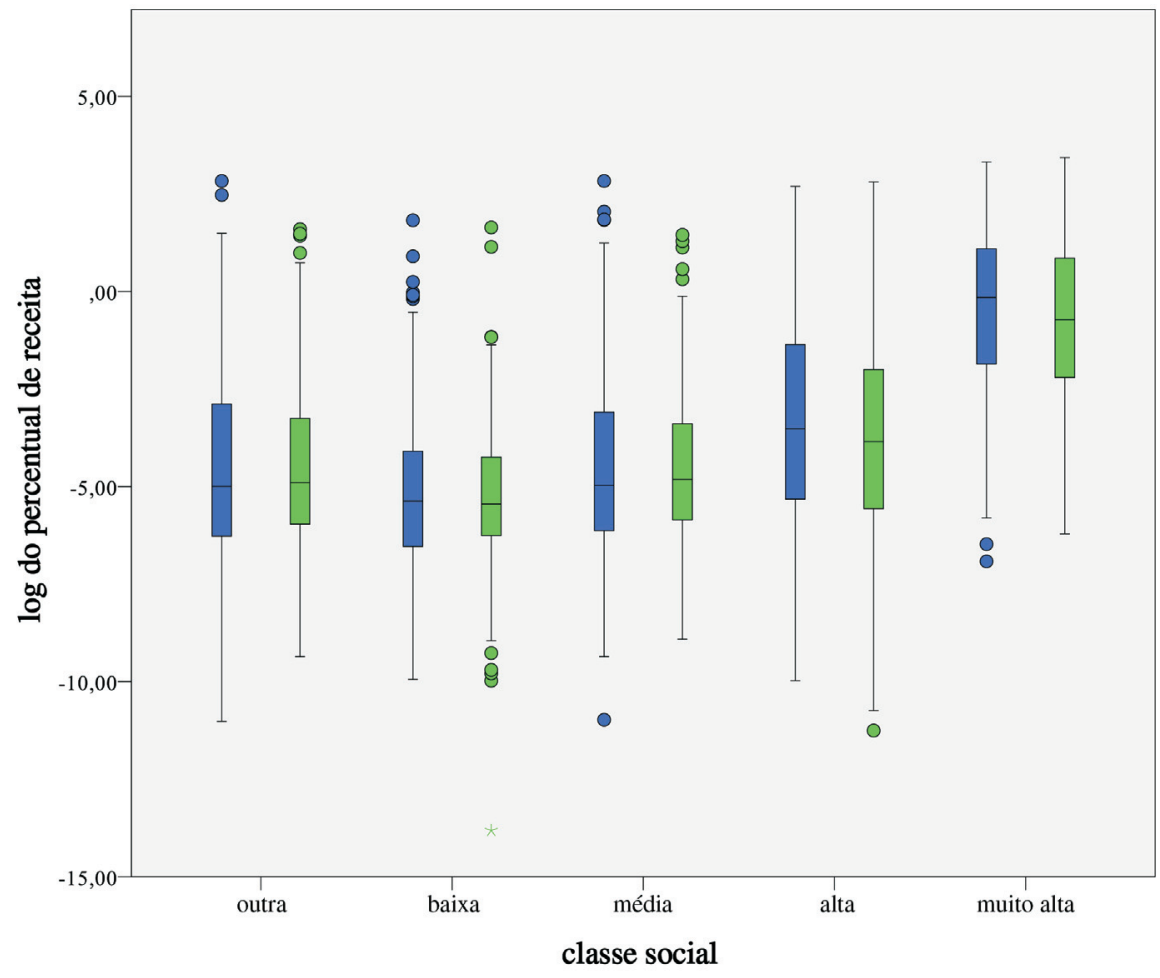

DESCRIÇÃO COR (BIN)

$\square$ BRANCA

NÃO BRANCA

Fonte: Os autores, a partir do Tribunal Superior Eleitoral (2017). 
necessidade de utilizar o log do percentual de recursos de campanha. pelos modelos de regressão linear da Tabela 3, que tomam como variável dependente o log do percentual de receita. Comparado ao modelo de regressão aplicado à votação, ser não branco possui um efeito negativo significativo na obtenção de recursos de campanha mesmo quando esse efeito é controlado por outras variáveis como sexo, ter diploma de Ensino Superior ou pertencer às classes alta ou muito alta. É verdade que esse efeito da cor tende a cair bastante quando controlado o efeito do gênero e da classe, mas ele ainda assim é comparável ao efeito de se ter concluído o Ensino Superior. Uma candidatura não branca apresenta em média $8,9 \%$ menos receita em comparação a uma candidatura branca, controladas as demais variáveis no modelo 4 .

Não brancos têm menos acesso a recursos de campanha do que candidatos brancos, mesmo quando se isola estatisticamente a origem de classe, o grau de instrução ou o sexo do candidato. É importante notar que o efeito do pertencimento racial opera uma inclinação maior na desigualdade entre as candidaturas em relação à votação. Apesar de não brancos receberem 8,9\% menos recursos do que brancos, o que implicaria uma diferença que poderia ser compreendida talvez como residual, a votação em não brancos chega a ser $23 \%$ menor, como observado anteriormente. Mas apesar da alta correlação entre numerários de campanha e votos recebidos, as receitas obtidas são apenas um dos recursos eleitoralmente valiosos nas eleições nacionais. Não apenas porque uma parte das receitas de campanha vêm dos partidos políticos e do financiamento público via fundo partidário, mas também porque os partidos possuem outras formas de privilegiar determinados candidatos, distribuindo tempo de televisão no horário político-eleitoral gratuito, por exemplo. Ademais, as votações nominais, analisadas na última seção, não são suficientes para estimar com precisão as chances eleitorais de um candidato. No nosso sistema de lista aberta com possibilidade de coligação, a distribuição das vagas é determinada pelo quociente partidário, determinado pela quantidade de votos recebidos por cada coligação eleitoral. Tudo isso torna fundamental avaliar a distribuição de candidatos brancos e não brancos nas diferentes agremiações partidárias brasileiras.

\section{Acesso a partidos competitivos}

Como o Gráfico 7 demonstra, há uma substantiva variação no percentual de não brancos nas listas partidárias de cada um dos 32 partidos que disputaram o pleito de 2014. Há desde casos como o PMDB, cujas candidaturas possuíam apenas $21 \%$ de não brancos, até o PCO, que lançou cerca de $67 \%$ de candidatos não brancos. Vale notar, também que, essas desigualdades na participação de não brancos não parecem acompanhar as tradicionais linhas ideológico-parti-

Tabela 3 - Modelos de regressão linear para o log do percentual da receita de campanha obtida em relação ao estado (variável dependente)

\begin{tabular}{|c|c|c|c|c|c|c|c|c|}
\hline & \multicolumn{2}{|c|}{$\begin{array}{c}\text { Modelo } 1 \\
(\mathrm{R} 2 \text { ajust. }=\mathbf{0 , 0 0 7})\end{array}$} & \multicolumn{2}{|c|}{$\begin{array}{c}\text { Modelo } 2 \\
(\mathrm{R} 2 \text { ajust. }=\mathbf{0 , 1 1 7})\end{array}$} & \multicolumn{2}{|c|}{$\begin{array}{c}\text { Modelo } 3 \\
(\mathrm{R} 2 \text { ajust. }=0,176)\end{array}$} & \multicolumn{2}{|c|}{$\begin{array}{c}\text { Modelo } 4 \\
(\mathrm{R} 2 \text { ajust. }=\mathbf{0 , 2 2 4})\end{array}$} \\
\hline & B & std. B & B & std. B & B & std. B & B & std. B \\
\hline (Constante) & $-3,159 *$ & & $-2,678 *$ & & $-3,533^{*}$ & & $-4,020 *$ & \\
\hline Não branco & $-0,415^{*}$ & $-0,085$ & $-0,339 *$ & $-0,070$ & $-0,157 *$ & $-0,032$ & $-0,089 *$ & $-0,018$ \\
\hline Feminino & & & $-1,738 *$ & $-0,331$ & $-1,652 *$ & $-0,315$ & $-1,455^{*}$ & $-0,278$ \\
\hline Ensino superior & & & & & $1,216^{*}$ & 0,247 & $0,743 *$ & 0,151 \\
\hline Classe alta/muito alta & & & & & & & $1,191^{*}$ & 0,246 \\
\hline
\end{tabular}

Fonte: Os autores, a partir do Tribunal Superior Eleitoral (2017).

* Significativo a $5 \%$. 
Gráfico 7 - Distribuição das candidaturas por cor em cada partido político (valores percentuais)

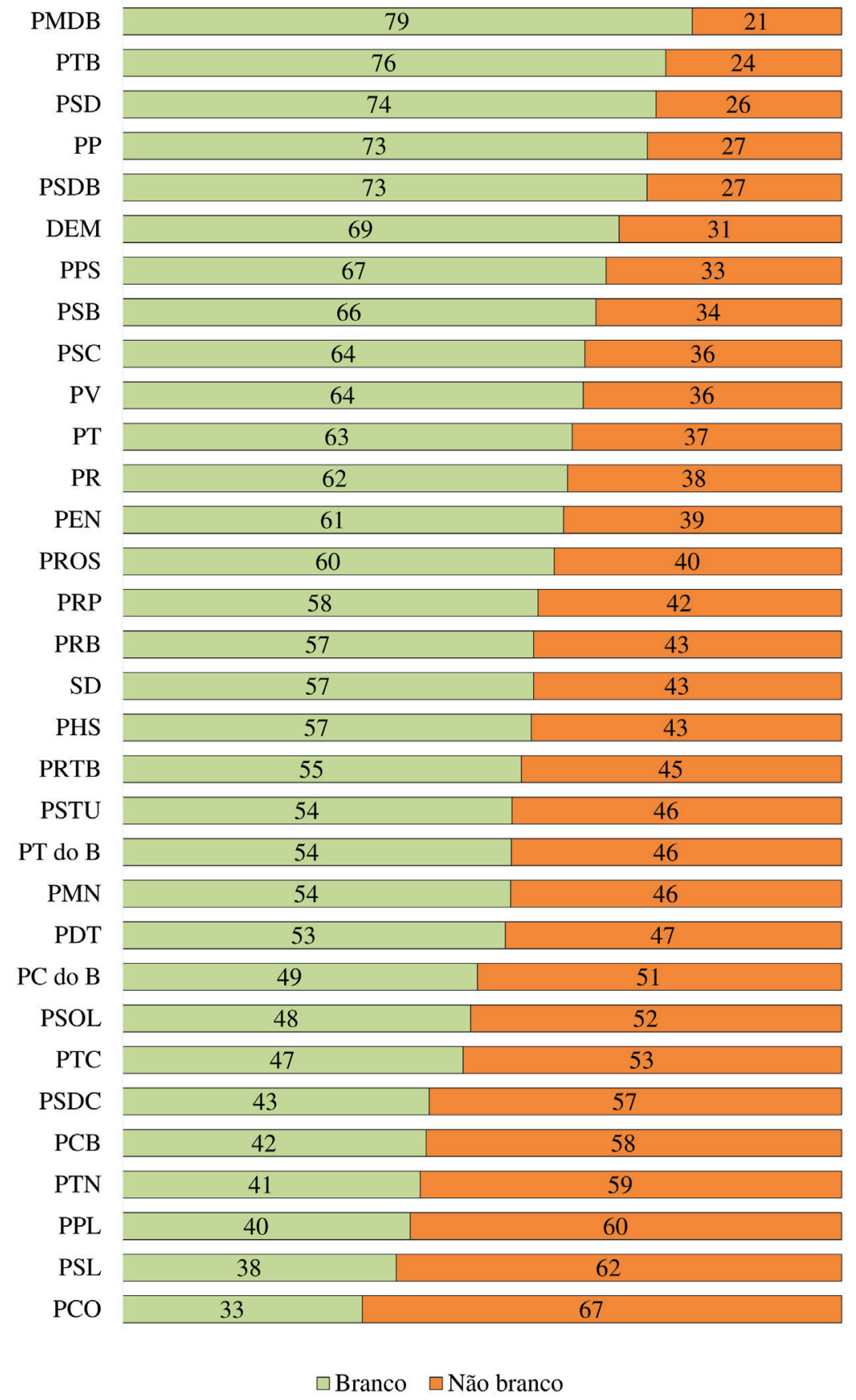

Fonte: Os autores, a partir do Tribunal Superior Eleitoral (2017).

dárias, como parte da bibliografia especializada apostava (Oliveira 1991). Partidos tradicionalmente considerados de "esquerda" como PSB e PPS lançaram mais de $60 \%$ de candidatos brancos, enquanto partidos mais à "direita" como PTN e PSDC apresentaram quase $60 \%$ de candidaturas não brancas.

No entanto, o Gráfico 7 já permite antever uma clivagem importante entre os partidos. De um lado, os partidos mais consolidados no sistema parecem possuir uma maior quantidade de brancos, enquanto os partidos menores e mais fracos eleitoralmente apresentam uma quantidade maior de candidaturas não brancas. Partidos grandes como PMDB, PSDB, DEM e PT costumam ter em média 70\% 
${ }^{6}$ Os partidos marcados com um asterisco disputaram suas primeiras eleições em 2014 e, por isso, foram encaixados nos grupos de acordo com sua votação nesse pleito. de suas nominatas compostas por brancos, enquanto partidos pequenos como PSDC, PCB, PTN, PPL e PSL, em média, 40\% de candidatos brancos.

Com base em uma classificação utilizada por Campos (2015), classificamos os 32 partidos de acordo com seu "tamanho". Considerando dados como o número de filiados declarados por cada partido, a bancada conquistada por cada um deles na Câmara dos Deputados Federais e a votação obtida nas eleições de 2012, os partidos foram divididos em três grupos: partidos grandes (PMDB, PT, DEM e PSDB), partidos médios (PDT, PTB, PP, PR, PSB, PPS, PCdoB, PV, PRB, SD*, PROS* e PSD) e partidos pequenos (PRP, PMN, PSOL, PSL, PSC, PTC, PTdoB, PSDC, PHS, PTN, PRTB, PCB, PPL, PSTU, PEN* e PCO) ${ }^{6}$ (Gráfico 8).

Grosso modo, os partidos maiores tendem a buscar ou atrair candidaturas brancas, enquanto os partidos menores tendem a lançar proporcionalmente mais candidatos não brancos. Como é difícil supor que essas preferências reflitam princípios ideológicos dos partidos, a hipótese mais provável é que os partidos menores tendem a adotar uma tática de seleção de candidaturas menos restrita, ou seja, um padrão de recrutamento chamado pela literatura internacional de catch-all. Provavelmente, isso abre mais oportunidades políticas para candidatos não brancos de classe inferiores. Se essa hipótese for verdadeira, os partidos menores também tenderão a recrutar menos candidatos de classes altas e muito altas, as mais interessantes no que concerne o potencial de votação. De fato, quanto mais um partido político privilegia candidatos de classe alta ou muito alta, menor é a proporção de não brancos em sua lista, como indica o Gráfico 9, expressada pela correlação de -0,61, pelo R de Pearson.

No entanto, o Gráfico 9 não nos permite dizer que a maior presença de brancos em um dado partido reflita uma preferência do mesmo por candidatos de classe alta. Quando observamos a classe de origem dos candidatos brancos e não brancos em cada legenda, percebemos que existem padrões distintos de recrutamento, como indica o Gráfico 10. Partidos como o PT e o SD, por exemplo, recrutam mais candidatos de classe alta do que o PMDB ou o PSDB. Mas, em termos relativos, recrutam mais candidatos não brancos de classe alta do que esses últimos. Não é nosso objetivo analisar em detalhe esses dados, mas apenas indicar não ser possível atribuir a relativa ausência de pretos e pardos em determinados partidos a um viés elitista de seleção de suas candidaturas. Embora se saiba que os não brancos brasileiros sejam oriundos de classes baixas em sua maioria, existem legendas que privilegiam candidatos não brancos de classe alta.

Gráfico 8 - Distribuição da somada das candidaturas por cor de acordo com o tamanho dos partidos políticos (valores percentuais)

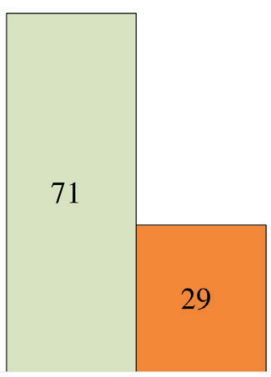

Grandes

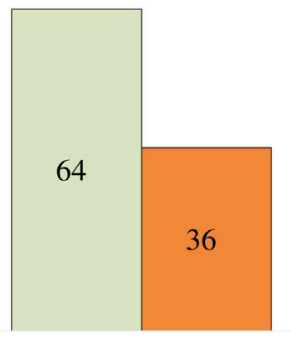

Médios

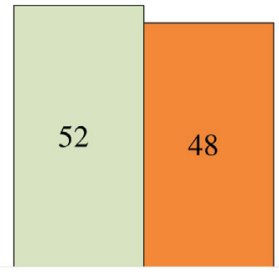

Pequenos $\square$ Branco $\square$ Não branco

Fonte: Os autores, a partir do Tribunal Superior Eleitoral (2017). 
Gráfico 9 - Matriz de correlação entre o percentual de candidatos de classe alta ou muito alta (Y) e o percentual de candidatos não brancos $(\mathrm{X})$ em cada partido

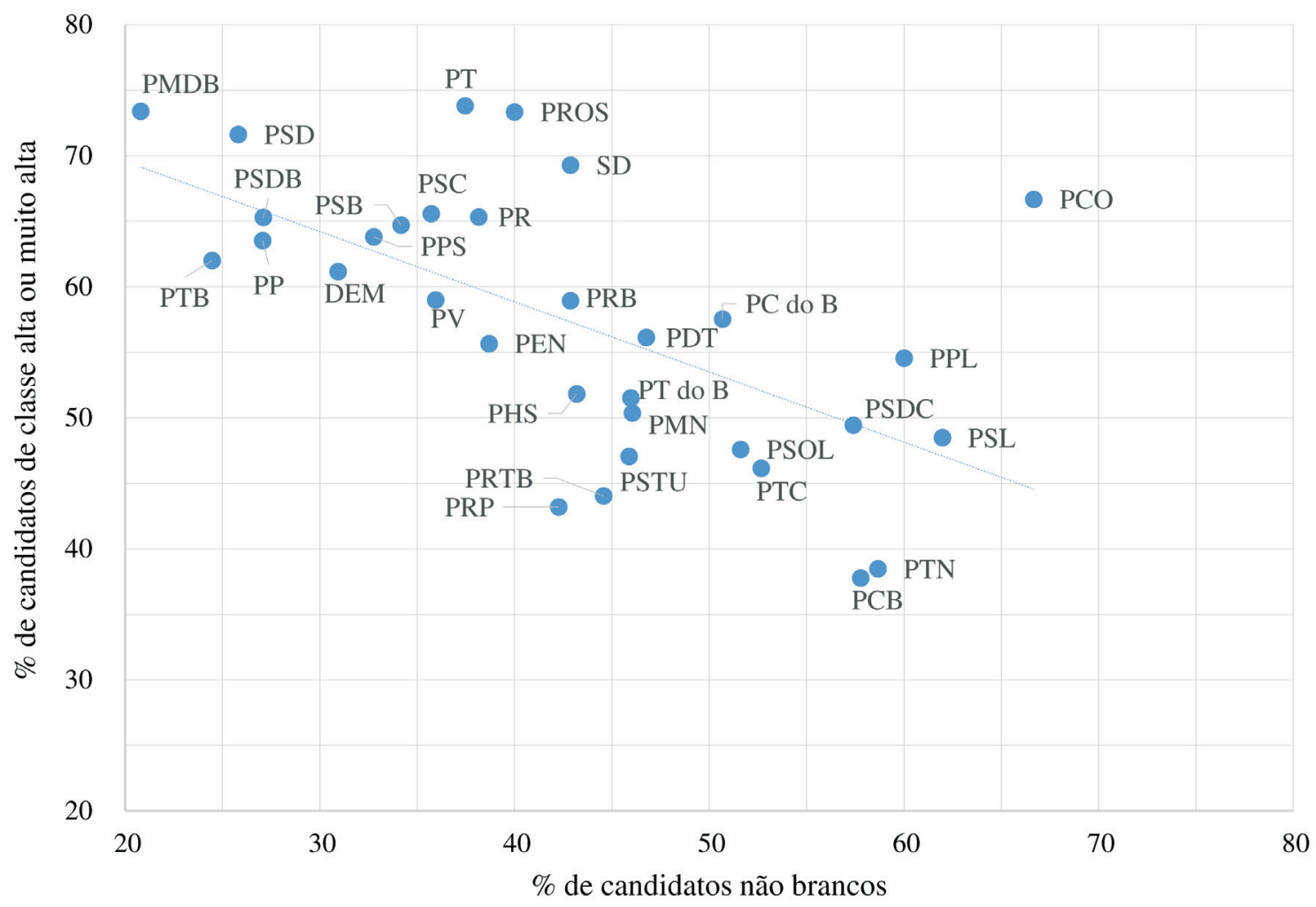

Fonte: Os autores, a partir do Tribunal Superior Eleitoral (2017).

\section{Conclusões}

Os dados das eleições de 2014 mostram um padrão já detectado em estudos-pilotos feitos a partir das eleições municipais de 2012 no Rio de Janeiro e em São Paulo (Campos 2015; Campos \& Machado 2015a; 2015b). Muito embora tais estudos se refiram a realidades bem mais restritas e tenham se baseado na heteroclassificação dos candidatos, é surpreendente como os achados se repetem. Em primeiro lugar, ainda que a proporção de não brancos nas listas partidárias seja menor do que a participação dos mesmos na população de cada unidade da federação, é difícil atribuir a sub-representação desse grupo a uma oferta carente de candidatos. Há uma certa associação entre a população não branca de cada estado e o percentual de candidatos não brancos lançados, mas tal associação se torna fraca quando comparamos população e eleitos.

Ao que parece, a origem de classe, combinada aos critérios de recrutamento partidário, explicam em grande medida a ausência de não brancos do parlamento. Como foi possível notar na terceira seção, ser de classe alta tem um impacto substantivo no percentual de votos recebidos. Ainda que ser não branco também tenha um impacto na votação, tal efeito não se revelou significativo de um ponto de vista estatístico. Ademais, partidos que costumam recrutar mais candidatos de classe alta e muito alta normalmente recrutam menos pretos e pardos para suas nominatas. E, ao que os dados indicam, essa tendência costuma acompanhar o grau de consolidação e competitividade das legendas, isto é, os partidos maiores e mais competitivos tendem a ser os que menos recrutam não brancos, enquanto os partidos menores e menos competitivos tende a recruta mais não brancos. 
Gráfico 10 - Proporção de candidatos em cada partido de acordo com a raça e classe* (valores percentuais)

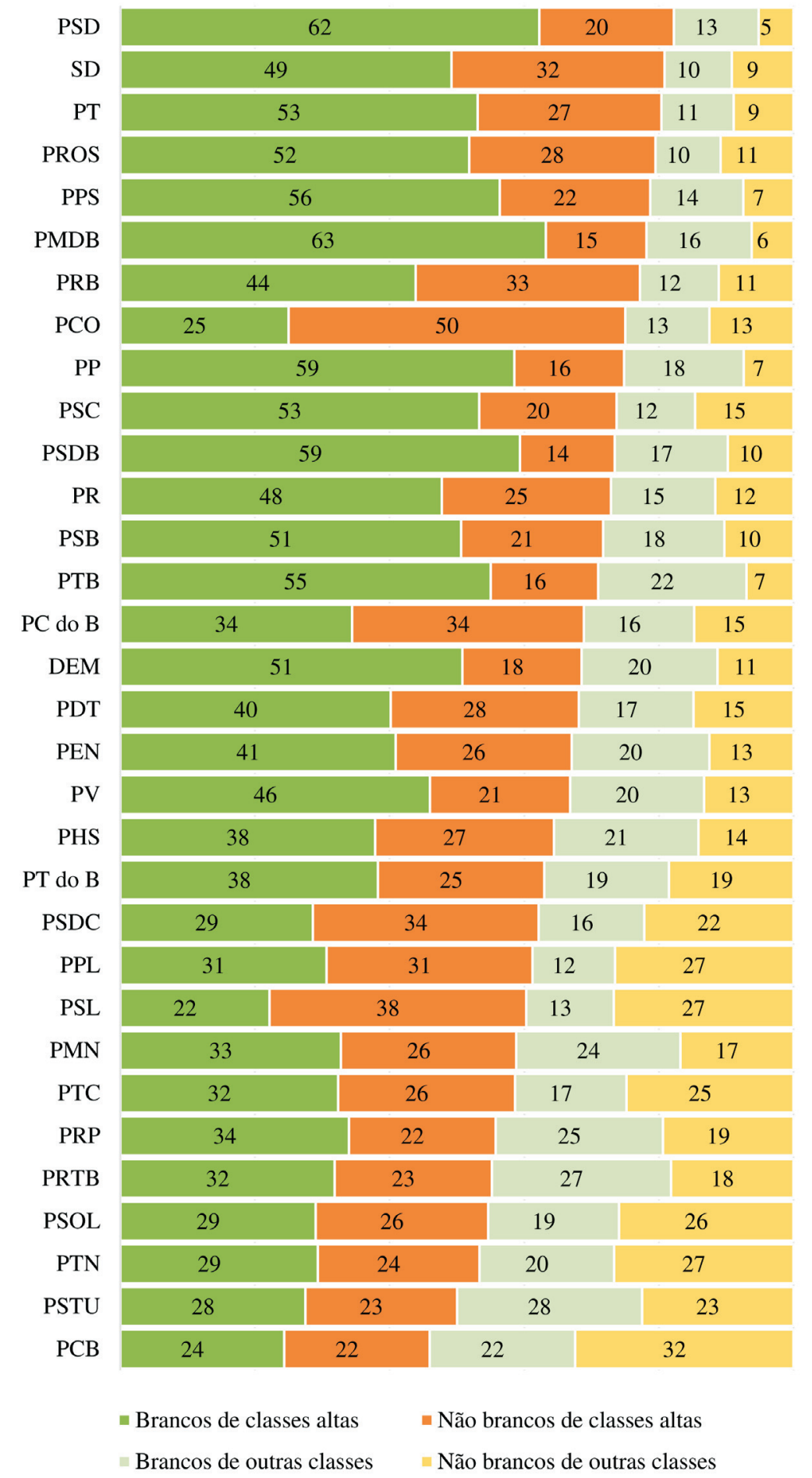

Fonte: Os autores, a partir do Tribunal Superior Eleitoral (2017).

* Foram excluídos dessa análise todos os candidatos com ocupação não identificada na base de dados do TSE.

Ainda assim, há um gargalo eleitoral que merece ser explorado com mais cautela: o acesso a recursos de campanha. Mesmo quando isolamos o efeito da 
origem de classe, candidatos não brancos permanecem tendo um menor acesso a financiamentos mais volumosos. A desvantagem é comparável em intensidade ao fato de não ter Ensino Superior, recurso social de grande valia nas disputas eleitorais.

O caminho pelo qual se concretiza esta desigualdade, entretanto, corre por um tortuoso caminho e deve ser visto em toda a sua complexidade. Existem candidaturas não brancas, mesmo que em menor número em relação às brancas, porém as primeiras não galgam o mesmo sucesso que as últimas. Uma leitura apressada pode atribuir esse efeito ao racismo do eleitorado brasileiro, mas tal diagnóstico superestima a capacidade de o eleitor definir a representação política para além das constrições sociais e institucionais do nosso sistema político.

Apesar de ter sido indicada a discrepância entre partidos de maior porte e de menor porte no acolhimento de candidaturas não brancas, esse efeito não deve ser observado de forma agregada, como o foi aqui, mas com base na dinâmica de cada distrito eleitoral (Cox 1997, pp.14-33), ambiente em que se constrói a interação entre predisposições sociais e oferta política, da qual o resultado é a representação política efetivamente.

Para além da compreensão específica sobre os efeitos das instituições, outros elementos que conformam a candidatura também carecem de consideração:

1) $\mathrm{O}$ efeito de o candidato ser um mandatário e poder se beneficiar com a exposição prévia na disputa pela reeleição;

2) O pertencimento a um grupo familiar com tradição política também facilitaria a conversão de capital para o acesso à política. A maior dificuldade de tratar deste tópico está na dificuldade extrema de obter esse tipo de informação para as candidaturas como um todo, uma vez que as informações efetivamente disponíveis sobre o tema são em sua quase totalidade ligadas apenas às candidaturas vitoriosas;

3) O tempo disponível de veiculação de campanha durante o horário eleitoral gratuito, que permite mensurar, inclusive, se haveria algum tipo de padrão de favorecimento em relação à pertença racial das candidaturas.

Esses elementos podem ser somados às análises para refinar a compreensão dos efeitos da raça nas chances de sucesso eleitoral dos candidatos. Os achados aqui apresentados servem mais para estimular uma agenda de pesquisa de um tema cuja sociedade brasileira não pode mais ignorar apelando a uma pretensa neutralidade das instituições democráticas.

Luiz Augusto Campos (lascampos@iesp.uerj.br) é Doutor em Sociologia pelo Instituto de Estudos Sociais e Políticos da Universidade Estadual do Rio de Janeiro (IESP-UERJ) e Professor do Programa de Pós-Graduação em Sociologia da mesma instituição. Vínculo Institucional: Instituto de Estudos Sociais e Políticos, UERJ, Rio de Janeiro, RJ, Brasil.

Carlos Machado (carlos.machado.unb@gmail.com) é Doutor em Ciência Política pela Universidade Federal de Minas Gerais (UFMG) e Professor do Instituto de Ciência Política da Universidade de Brasília (UnB). Vínculo Institucional: Instituto de Ciência Política, UnB, Brasília, DF, Brasil.

\section{Referências}

Bueno, N. \& Dunning, T., 2013. Race, Resources, and Representation: Evidence from Brazilian Politicians. In Seminário Race, class, and representation: evidence from Brazilian politicians. São Paulo.

Campos, L.A., 2015. Socialismo moreno, conservadorismo pálido? Raça e recrutamento político nas cidades de São Paulo e Rio de Janeiro (2012). Dados, (57)2, pp.689-719. DOI: 10.1590/00115258201556

Campos, L.A. \& Machado, C., 2015a. A cor dos eleitos: determinantes da sub-representação política dos não brancos no brasil. Revista Brasileira de Ciência Política, 16, pp.121-151. DOI: 10.1590/0103-335220151606 
2015b. A Raça dos (In)eleitos. Insight Inteligência, (17)67, pp.60-72.

Codato, A.; Costa, L.D. \& Massimo, L., 2014. Classificando ocupações prévias à entrada na política: uma discussão metodológica e um teste empírico. Opinião Pública, (20)3, pp.346-362. DOI: 10.1590/1807-01912014203346

Cox, G.W., 1998. Making Votes Count: Strategic Coordination in the World's Electoral Systems. New York: Cambridge University Press.

Gaxie, D., 2012. As lógicas do recrutamento político. Revista Brasileira de Ciência Política, 8, pp.165-208. DOI: 10.1590/s0103-33522012000200007

Lemos, L.B.; Marcelino, D. \& Pederiva, J.H., 2010. Porque dinheiro importa: a dinâmica das contribuições eleitorais para o Congresso Nacional em 2002 e 2006. Opinião Pública, (16)2, pp.366-393. DOI: 10.1590/s0104-62762010000200004

Mansbridge, J., 1999. Should Blacks Represent Blacks and Women Represent Women? A Contingent "Yes". The Journal of Politics, (61)3, pp.628-657. DOI: 10.2307/2647821

Marques, D., 2012. Determinantes de carreiras políticas no Brasil, na Argentina e no Uruguai: uma abordagem comparativa entre deputadas e deputados. Tese de Doutorado. Belo Horizonte: Universidade Federal de Minas Gerais.

Meneguello, R.; Mano, M.K. \& Gorski, C., 2012. Alguns condicionantes do déficit representativo de mulheres e negros na política. In R. Menguello et al. eds. Mulheres e negros na política: estudo exploratório sobre o desempenho eleitoral em quatro estados brasileiros. Campinas: Centro de Estudos de Opinião Pública.

Michels, R., 1982. Sociologia dos partidos políticos. Brasília: Editora da UnB.

Norris, P., 1997. Passages to Power: Legislative Recruitment in Advanced Democracies. Cambridge, UK: Cambridge University Press.

Norris, P. \& Lovenduski, J., 1995. Political Recruitment: Gender, Race and Class in the British Parliament. Cambridge, UK: Cambridge University Press.

Oliveira, C., 1991. O Negro e o Poder no Brasil: os negros candidatos a vereador em Salvador, em 1988. Caderno CRH, suplemento, pp.94-116.

Phillips, A., 1995. The Politics of Presence. New York: Oxford University Press.

Williams, M., 2000. Voice, Trust, and Memory: Marginalized Groups and the Failings of Liberal Representation. Princeton: Princeton University Press.

Young, I.M., 2000. Inclusion and Democracy. New York: Oxford University Press.

\section{Outras fontes}

Tribunal Superior Eleitoral, 2017. Repositório de dados eleitorais. Disponível em: http://www.tse.jus.br/eleicoes/estatisticas/ repositorio-de-dados-eleitorais. Acesso em: 21 fev. 2017. 


\title{
What Averts Black and Browns of Political Representation? A 2014 Legislative Election Analysis
}

\begin{abstract}
Even a casual observer of Brazilian politics perceive the exclusion of blacks and browns from the Brazilian decision-making arenas. Nevertheless, the absence of records on the color/race of Brazilian politicians always difficult evaluating this underrepresentation and its possible causes. However, since the 2014 elections, the Superior Electoral Court computes the race/color of registered candidates, partially circumventing these difficulties. In this article, we use these data to gauge how underrepresented blacks and browns are in the Lower House and, above all, test some explanatory hypotheses of this phenomenon. Blacks and brows have reduced electoral chances compared to those of whites because of multiple factors: source class, access to campaign resources and competitive party structures. All this suggests that measures that seek to make the most diverse political representation should consider the complexity of the obstacles to the black and brown population in Brazil.
\end{abstract}

KEYWORDS: race; black people; political representation; elections; political recruitment.

This is an Open Access article distributed under the terms of the Creative Commons Attribution Non-Commercial License which permits unrestricted non-commercial use, distribution, and reproduction in any medium provided the original work is properly cited. 